$\xi=-1$

\title{
Academic Inculcating Behavior Scale and Validation using CSE and PsyCap in Diverse Faculty Members
}

\author{
Duchduen Bhanthumnavin \\ The Graduate School of Social and Environmental Development, National Institute of Development Administration, Bangkok 10240, \\ Thailand
}

\begin{abstract}
Academic Inculcating Behavior Scale (AIB) for faculty members in university was constructed for assessing and developing university lecturers' quality. There were four studies with the total sample of 828 university faculty members in Thailand. Ninety items were assembled, but only 31 items were selected by a group of educational-behavioral science experts. In study1 with 100 respondents, 25 out of 31 items met the criteria for item quality. Results from EFA in study 2 using 300 new respondents revealed a three-factor model (4 items for giving positive reinforcement, 3 items for giving social support, and 4 items for modeling and preventive action) with the total of 11 items and with $59.131 \%$ of the total variance accounted for. This model was confirmed by CFA with another 300 respondents in study 3 . In study 4, using 128 respondents, criterion-related validity of the AIB scale score was demonstrated by the predictive power of four independent variables by performing multiple regression analysis. Three independent variables which were positively related to AIB were CSE, PsyCap, and level of education of the respondents. Furthermore, it was found that faculty members with doctoral degree reported higher score of AIB than the ones with Master's degree. The results showed that AIB measure has acceptable qualifications. However, more predictors of AIB should be investigated and confirmed by experimental studies. Consequently, the necessity to carry out intervention program for faculty members can be met with success. This will benefit the students, as well as ensuring that higher educational institutions can perform their expected functions.
\end{abstract}

Keywords: Academic Inculcating Behavior (AIB), Core Self-Evaluation (CSE), Psychological Capital (PsyCap), Faculty Member, Factor Analysis

\section{Introduction}

College education is becoming a necessity rather than a luxury for new generations in most modern societies. Knowledge-based economy adopted in these societies demands more knowledge production, knowledge seeking and knowledge usage. Therefore, higher educational institutions have to put more emphasis on producing future graduates with higher ability and stronger habit for exploring and exploiting new and advanced knowledge. Acquiring new knowledge and put it into good use can lead to adoption of technical innovation and success of one's career.1-2

To meet the national qualification of Thailand Qualifications Framework for Higher Education (TQF), as well as, the international standards, such as, ASEAN University Network Quality Assurance (AUN-QA) or Educational Criteria for Performance Excellence (EdPex), college and university faculty

members have full responsibility in inculcating their students in various areas, such as, seeking new and advanced academic knowledge, thinking more critically for making appropriate decision and also committing to ethical and moral responsibilities, among other things3.

As for the inculcating of the motive and habit to explore and exploit new knowledge in students, most faculty members often displace their responsibilities to college library and librarians4.Thus, most graduates may leave their university with less qualification due to their lecturers' low or absence of inculcating behaviors. The remedy to this world-wide problem is research to give light to the determinants of teacher's inculcating behavior and use them in their intervention program. Both research and interventions require assessments to measure this behavior and other related variables.

Therefore, the present study aims at constructing a new academic inculcating behavior (AIB) scale for use with faculty members in college and university. Its preliminary validity and reliability of the scores of this new scale are investigated. The whole AIB measure is presented in this article to encourage its use in future studies.

\section{INCULCATING BEHAVIOR OF FACULTY MEMBERS}

Faculty members are the majority of academic personnel in higher educational institutions. The positions can be filled by holders of master's degree or doctoral degree. Their contribu-tions to the institutions are teaching, researching and offering academic services to the society 5 in the form of corporate social responsibility to schools and communities. The major role of most faculty members is teaching in undergraduate and graduate levels. Undergraduate teaching is being emphasized in this study. Measuring of teaching as work performance of higher institutional faculty members have come to the attention of educational and psychological researchers only recently6.Their research output in the forms of numbers of publications in academic journals and citations have been among popular yardsticks of their career success 7-8. But other had offered more appropriate indices for developing countries $9-12$

Workload on teaching has been defined as number of hours per week that one considered as working on duty. The weekly hours worked inside and outside the university were combined. One study on 13 countries in Europe, America, and Asia reported that 
there was an increase in the average number of work per week from 1984 (43.900 hours) to 2008 (49.300 hours). The faculty members worked longer hours when class was in session. Moreover, teaching took more time than research activities (19.600 and 15.700 hours per week, respectively)6,13

The present study reports a construction of a new type of behavior of the faculty members. It is called "Academic Inculcating Behavior Scale" This measure reflects the new academic identity (Henkel, 2005; Quigley, 2011) of college teachers in showing interest to students' response and academic activities, by giving social support and positive reinforcement to encourage appropriate academic behavior of students. They should be good mentors and models by their own activity and work success9. In many circumstances, preventive measures should be another strategy as well. These are the techniques for inculcating of knowledge, belief, value, behavior and habit. In this measure, the contents for inculcating are exploration and exploitation14-15 of new academic knowledge in and outside of class assignments. The numerous strategies for inculcating students are based on the behaviors of effective and successful leaders towards their subordinates16-17, as well as between teachers and students18 or between parent and the child, especially in Thailand19.

Thus, the AIB was defined as the strategies that faculty members use to stimulate and encourage sustainable belief, value, and practice of their students in 4 different ways, namely, giving social support, positive reinforcement, being good model, and using preventive measures. The reporting behaviors from the faculty members was limited to the areas of exploration and exploitation of new knowledge. This definition was used as a basis for constructing 90 items with both positively and negatively worded.

\section{Research Method}

The samples in these four studies were faculty members in education and social science. The total of 828 Thai faculty members from all over the country for at least 50 universities completed the set of questionnaires. Of these numbers, it was divided into four studies as follows. Study 1 for item quality used 100 respondents. Study 2 for exploratory factor analysis (EFA) employed 300 respondents. Study 3 for second-order confirmatory factor analysis (CFA) used 300 respondents. Study 4 for validation of this new measure (AIB), 128 respondents participated.

Items of the Academic Inculcating Behavior Scale (AIB) were generated according to Bandura's theory (1977). Originally, 90 items were generated by the researcher. Only 31 items were selected by a group of Thai educational-behavioral science experts.

\section{Results and Discussion}

\subsection{Study 1: Item Quality}

Item quality was decided by two criteria. First, for item discrimination (t-ratio), t-value should be more than 1.96 (significant level at .05)20-21 .Second, for item-total correlation, $\mathrm{r}$ should be at least 0.30022 .

After trying out these 31 items to 100 faculty members, and calculating t-ratios and item-total correlations, six items were excluded. Thus only 25 items remained as an input to the next step

\subsection{Study 2: Exploratory Factor Analysis}

In this step, the 25 selected items were proceeded to exploratory factor analysis (EFA) using a new group of 300 university lecturers. Three criteria23 were used as follows: 1) Kaiser-Meyer-
Olkin Measure of sample adequacy (KMO) should be at least 0.600 2) chi-square must be significant and 3) Eigenvalue of each dimension must be at least 1.000 .

Results from EFA revealed three-factor model $(\mathrm{KMO}=0.774$ $\square 2=921.137, \mathrm{p}$-value $=.000, \mathrm{df}=55)$. The first dimension consisted of 4 items on giving social reward or positive reinforcement to the student when he (or she) behave accordingly (explore or exploit new knowledge) with the eigenvalue of 3.435. These four items could explain this construct with $31.231 \%$. The second dimension consisted of 3 items on giving social support to students when they intend to carry out the suggested activities with the eigenvalue of 1.863 . These three items added the predictive power of $16.940 \%$, resulted as the total predictive power of $48.171 \%$. The third dimension consisted of 4 items on good role modeling and prevention of the students' undesirable actions with the eigenvalue of 1.206. These four items added the predictive power of $10.960 \%$, resulted as the total predictive power of $59.131 \%$. The total of AIB was 11 items (see Appendix).

\subsection{Study 3: Confirmatory Factor Analysis}

Second-order confirmatory factor analysis was performed using a measure with other 300 data from faculty members. There were three criteria23 in this step for a measure with number of items less than

12 items and samples size more than 250 , as follows: 1 ) chi-square should not be significant. 2) CFI and TLI should be more than 0.950 3) RMSEA should be less than 0.070. Furthermore, SRMR should be less than 0.08024 .

Results from CFA indicated fit model $(\square 2=53.233$, $\mathrm{p}$-value $=$ $.078, \mathrm{df}=40, \mathrm{RMSEA}=0.033, \mathrm{CFI}=0.984, \mathrm{TLI}=0.978$, and $\mathrm{SRMR}=0.039)$ as Figure 1.

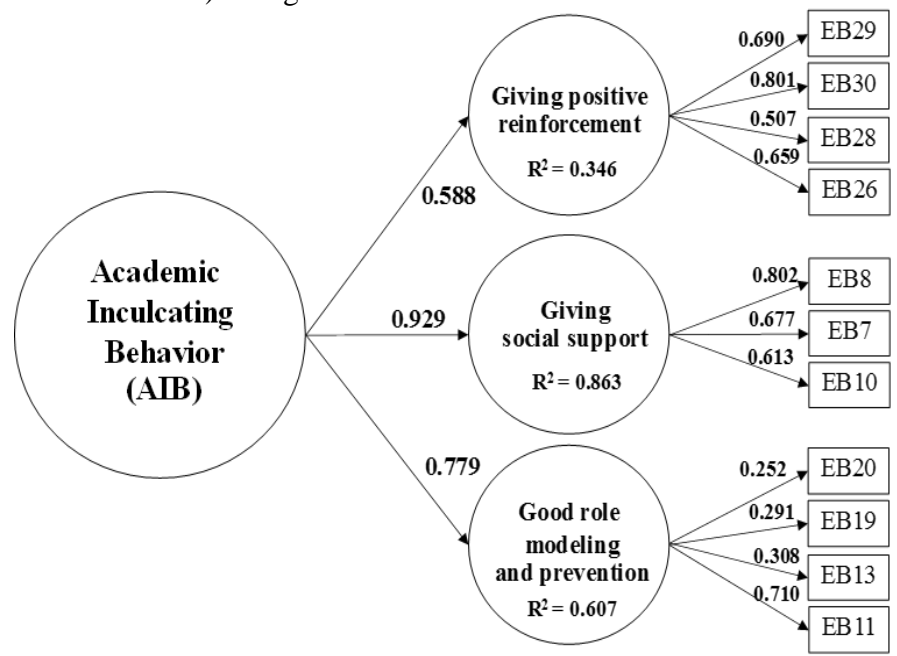

Fig. 1 Second-order confirmatory factor analysis of Academic Inculcating Behavior (AIB)

\subsection{Study 4: Reliability And Validity}

In this step, reliability and validity of AIB were considered. Data from a group of 128 faculty members were employed. The reliability of the AIB score with 11 items was 0.808 . In order to validate this newly constructed measure, two biosocial variables and two standardized psychological constructs were employed as the predictors of AIB. They were 1) psychological capital (PsyCap) consisting of four dimensions, namely, hope, self-efficacy, optimism, and resilience. The score reliability of 12-item PsyCap measure in this study was 0.856 . 2) core self-evaluation (CSE) consisted of 4 dimensions: self-esteem, locus of control, neuroticism, and general self-efficacy (Judge, et al, 2003). The total of 12 items yielded the score reliability of 0.841 . These two measures were self-report in terms of summated rating scale. Each item was attached with 6-unit rating scale. 3) age of the respondents, and 4) educational level. 
Previous study indicated that PsyCap was positively related to work performance 25-29. As for CSE, study of 411 Thai cabin crews 30 revealed that the higher the CSE score of these respondents, the more they were higher on the in-fight service behavior and organizational citizenship behavior $(r=0.440$ and 0.500 , respectively). Similar results were found in several studies31-32. Therefore, it is hypothesized that in Thai faculty members, AIB can be validated by CSE and PsyCap together with age and level of education.

Results from Table 1 revealed that educational level, psychological capital, and core self-evaluation were positively and significantly related to AIB. In addition, CSE played important role as follows. High CSE scorers were the ones with 1) high AIB score $(r=0.492), 2)$ high PsyCap score $(r=0.495)$, and 3$)$ doctoral degree $(r=0.178)$. As expected, the doctoral degree holders were older than the master's degree holders $(r=0.244)$.

The results in this study were consonant with previous studies such as CSE positively correlated with PsyCap $(r=0.600)$ in 404 management students26.. On the other hand, PsyCap correlated with job performance $(r=0.481)$ in 660 Sri Lanka bankers 25 , while the present study found $r=0.412$ in Thai faculty members.

Table 1 Intercorrelation of variables in the study

\begin{tabular}{|c|c|c|c|c|c|c|}
\hline Variables & Mean & SD & 1 & 2 & 3 & 4 \\
\hline 1. age & 486.950 & 103.996 & 1.000 & & & \\
\hline 2. edlev & 1.463 & 0.501 & $.244^{* *}$ & 1.000 & & \\
\hline 3. PsyCap & 56.523 & 6.486 & 0.082 & 0.091 & 1.000 & \\
\hline 4. CSE & 51.773 & 7.498 & 0.146 & $.178^{*}$ & $.495 * *$ & 1.000 \\
\hline 5. AIB & 49.180 & 7.348 & 0.174 & $.261 * *$ & $.412^{* *}$ & $.492^{* *}$ \\
\hline
\end{tabular}

Note: $* \mathrm{p}<.05, * * \mathrm{p}<.01$. edlev $=$ educational level, PsyCap $=$ psychological capital, $\mathrm{CSE}=$ core self-evaluation, $\mathrm{AIB}=$ Academic Inculcating $\mathrm{Be}$ havior.

By performing MRA, using age, educational level, psychological capital, and core self-evaluation as independent variables to predict AIB, it was found that these four variables could accounted for $31.300 \%$ of the variance of AIB. The most important predictor was core self-evaluation, followed by psychological capital, and educational level (Beta $=.319, .228$, and .178 , respectively).

The total sample mean of AIB was 49.180 with SD of 7.348 with $95 \%$ CI of 47.900 to 50.520. Result from t-test comparing AIB scores according to educational level of university lecturers (66 master holders vs. 57 Ph.D. holders), it was found that Ph.D. holders showed higher AIB score than Master's degree holders ( $\mathrm{t}$ $=8.845, \mathrm{p}$-value $=0.004$; Master's mean $=47.439, \mathrm{DS}=7.850$, $95 \% \mathrm{CI}=45.51$ to 49.37 ; and Ph.D.'s mean $=51.263, \mathrm{SD}=6.140$, $95 \% \mathrm{CI}=49.630$ to 52.890 )

\section{Conclusions}

The AIB measure constructed in this study is intended to use for assessing faculty members' inculcating behavior, especially in the aspect of exploration and exploitation of knowledge of the undergraduate students. Exploratory and confirmatory factor analyses were performed. Inculcating behavior or skills of teachers was recently studied emphasizing critical thinking 33 .. In this study, three important strategies were extracted, which were giving positive reinforcement, giving social support, and being good role model and prevention. These strategies supported the positive psychology approach34 which encourage a person to think and act in good ways in order to change or to develop desired psychological characteristics and behaviors of self, as well as others.

This study also confirmed the importance of core self-evaluation on work behavior which in this case was academic inculcating behavior of faculty members. The finding from MRA indicated that core self-evaluation was the most important predictor of AIB. Furthermore, this study added a new evidence of the importance of psychological capital on a new type of work behavior. The findings from MRA revealed that psychological capital was also the important predictor of AIB.
It is expected that future experimental results will show that CSE and PsyCap are the antecedents of AIB. All the psychological traits and AIB can be enhanced to strengthen the important academic identity of faculty members and yield greater benefit to the new generations to come.

\section{Acknowledgements}

This article is a part of research project "Empirical construction of measures of psychological characteristics and training efficiency on psycho-moral strength of learners and their validation in Thai university lecturers" under the umbrella of research plan "Psycho-moral strength in research and training of lecturers for students' development" which was financially supported by the Annual Government Statement of Expenditure Year 2017. Research also would like to thank National Institute of Development Administration (NIDA) for additional other financial and infrastructural supports.

\section{References}

[1] N Ibrahim, A. M. Rizal, M. Husin, and S. Kamarudin, Adv. Sci. Lett. 234 (2017).

[2] S. Irum, K. Ismail, and A.Muhammad, Adv. Sci. Lett. 239 (2017).

[3] Amer. Psy. Assoc., Amer. Psy, 71, 2 (2016).

[4] J.M.B. Nunes, S. Kanwal, and M. Arif, Proc IFLA2017 Know. Man. Sat. Conf., Poland, pp. 1-16.

[5] J.P. Sampson, Jr., M.P. Driscoll, D.F. Foulk, and P.S. Carrol, (Online). Florida State University, FL, http://fda.fsu.edu/sites/g/files/imported/storage/original/ application/c031a61b34e2d87ef142b20b3225c024.pdf.

[6] P.J. Bentley, and S. Kyvik, High Ed., 634 (2012).

[7] R.K. Toutkoushian, S.R. Porter, C. Danielson, \& P.R. Hollis, High. Ed., 44, 2 (2003).

[8] N.Sombatsompop, S.Chancheewa, T.Markpin, N. Premkamolnetr, S Ittiritmeechai, C.Wongkaew, W.Yochai, and P.Ratchatahirun, P. J.Lib. \& Inf. Sci., 17, 3 2012).

[9] D. Bhanthumnavin, Int J Psy and Beh. Sci, 5, 5 (2015).

[10] D. Bhanthumnavin, J. Beh Sci, 23,2 (2017).

[11] F.Osarch, and C.S. Wilson, Scientometrics, 39, 3 (1997).

[12] R. Sancho., Scientometric, 23, 1 (1992).

[13] S. Kyvik, High. Ed., 67, 1 (2013).

[14] D.Good, and E. Michel, J. of Psy., 147, 5 (2013).

[15] M.Maletic, D.Maletic, J.J.Dahlgaard, and S.M. Dahlgaard-Park, J. of Cle. Pro., 79, 0 (2014).

[16] .B.M.Bass, B.J.Avolio, D.I.Jung, and Y.Berson, J. of Appl. Psy, 88, 2 (2003).

[17] D.Zohar, and G. Luria, J. of Safe. Res., 34, 5 (2003).

[18] D. Bhanthumnavin, J of Beh. Sci, 21, 1(2015).

[19] C. Suvannathat, D. Bhanthumnavin, P. Sukontatharp, L. Ohuappirom, and D. Keats (editors), Handbook of Asian child development and child rearing practices. Bangkok, Thailand (1985).

[20] J. H. McMillan, and S. Schumacher, Research in Education. A Conceptual Introduction (5th ed.). Longman, New York (2001).

[21] J. C. Nunnally, Psychometric Theory. McGraw-Hill, New York (1967).

[22] E.Cristobal, C.Flavian, and M. Guinaliu, Man. Sr. Qual, 17, 3 (2007).

[23] J.F. Hair, W.C. Black, B.J. Babin, and R.E. Anderson, Multivariate Data Analysis. (7th Edition), Pearson, New York (2010).

[24] L.Hu, and P.M.Bentler, P. M., Psy. Meth, 3, O(1998).

[25] S. Kappagoda, H.Z.F.Othman, and G. DeAlwis, J. of Hum. Res. And Sus. Stu., 2, 2(2014).

[26] F.Luthans, B.J.Avolio,J.B.Avey, and S.M.Norman, Pers.Psy., 60 , 3(2007).

[27] S.J.Peterson, F.Luthans, B.J.Avolio,F.O.Walumbwa, and ZZhang, Pers.Psy, 64, 2(2011).

[28] P.Ramandei, Ad.Sci.Lett,23, 8(2017).

[29] F.Sarwar, and S.A.P.A.Rahman, Ad.Sci.Lett, 23, 9(2017).

[30] D. Supasamut, Integration of psychological and situational antecedents of work behavior in cabin crew (Ph.D. Dissertation). Thailand. National Institute of Development Administration, 2015.

[31] J.E.Bono, and T.A.Judge, Euro. J. of Per., 17 S1(2003).

[32] D.Bhanthumnavin. Antecedents of readiness and potential to be- 
come researchers in different types of individuals : Researchers (Research Report). National Institute of Development Administration, Thailand (2015).

[33] J.A.Baser, R. Saion, S.S.A.Manap,A.Hasan, and A.R. Abdul Razzaq, Adv.Sci.Lett, 22, 12(2016).

[34] M.E.P.Seligman, and M. Csikszentmihalyi, Amer. Psy, 55, 1(2000).

\section{Appendix}

Academic Inculcating Behavior Scale (AIB) (11 items)

EB29 I tell my students to be proud of themselves when they can find new information as I have suggested (+)

EB30 I praise my students when they can seek new knowledge as planned $(+)$

EB28 If my first suggestion failed, I will find a new way to motivate my students to put more effort in information search. (+) EB26 I encourage my students when they show their enthusiasm in seeking more data from different sources. $(+)$

EB8 I usually do not recommend my students to read easier papers in order to increase their interest in reading the text. (-) EB7 I do not suggest to my students to use what I have just taught to answer questions in class (-)

EB10 Many of my students have special knowledge or skills, but I do not recommend them to make use of it. (-)

EB20 There is little chance that students can have good models from teachers in making use of their academic knowledge. EB19 Students have little chance to observe a good model from teacher who makes use of his or her knowledge to develop new project.

EB13 I do not need to encourage my students because good students must have a habit of reading and searching for new knowledge.

EB11 I usually avoid giving feedback about the work of my students because I feel that it is a waste of time.

This summated rating scale, each item accompanied with 6-unit rating ranges from $1=$ "not true at all" to $6=$ "Extremely true". The scores must be reversed for negatively worded items. 